\title{
Pengenalan attitude heading reference system bagi himpunan mahasiswa dan alumni Prodi Teknik Elektro Institut Teknologi Dirgantara Adisutjipto
}

\author{
Freddy Kurniawan", Lasmadi, Sutjianto Sukarno \\ Program Studi Teknik Elektro Institut Teknologi Dirgantara Adisutjipto \\ Email Korespondensi: "freddykurniawan@itda.ac.id
}

Received March 23, 2021; Revised April 4, 2021; Accepted April 19, 2021

\begin{abstract}
Abstrak
Pengetahuan avionik merupakan hal yang mendalam sangat diperlukan bagi alumni prodi Teknik Elektro Institut Teknologi Dirgantara Adisutjipto. Dengan diberlakukannya kurikulum 2019, mahasiswa prodi ini telah dibekali pengetahuan avionik sesuai dengan target. Namun pengetahuan ini belum sepenuhnya didapat bagi angkatan 2016 dan sebelumnya dan juga alumni Teknik Elektro. Untuk itulah diperlukan program untuk memberikan pengetahuan avionik secara lebih mendalam kepada mereka. Program pengabdian masyarakat ini memberikan materi avionik Attitude and Heading Reference System (AHRS) kepada para mahasiswa angkatan 2016 dan sebelumnya dan juga alumni. Program ini diwujudkan dalam bentuk webinar dan dapat diikuti oleh masyarakat. Lebih jauh lagi, webinar ini juga dapat diikuti kapan saja di channel youtube dan pengetahuan AHRS dapat disebarluaskan kepada masyarakat.
\end{abstract}

Kata Kunci: avionik; Attitude and Heading Reference System (AHRS)

\begin{abstract}
Avionics knowledge is essential and necessary for alumni of the Adisutjipto Institute of Aerospace Technology Department alumni. With the implementation of the 2019 curriculum, students of this department have been equipped with avionics knowledge according to the target. However, this knowledge has not been fully obtained for the 2016 and previous batches and also for Electrical Engineering alumni. For this reason, a program is needed to provide them with more in-depth avionics knowledge. This community service program will provide avionics material Attitude Heading Reference System (AHRS) to students of class 2016 and before and also alumni. This program is realized in the form of webinars and can be followed by the community. Furthermore, this webinar can also be followed at any time on the YouTube channel and AHRS knowledge can be disseminated to the public.
\end{abstract}

Keywords : avionics; Attitude and Heading Reference System (AHRS)

\section{PENDAHULUAN}

Saat ini, dunia transportasi udara telah berkembang sangat pesat. Pesawat terbang sejatinya hanyalah suatu alat trasnportasi untuk membantu manusia dalam melakukan suatu perjalanan yang jauh. Akan tetapi, kebutuhan manusia tidak hanya sebatas itu, beberapa orang mungkin memiliki suatu pekerjaan yang dikerjakan selama dalam perjalanan tersebut, dan juga ada beberapa yang akan cepat bosan selama perjalanan tersebut. Maka dari itu, saat ini pesawat sudah dilengkapi dengan berbagai hiburan dan berbagai infrastruktur yang dapat menunjang semua itu.

Mulai tahun akademik 2019/2020 ini, proses pendidikan di Teknik Elektro Institut Teknologi Dirgantara Adisutjipto (ITDA) menggunakan kurikulum 2019. Kurikulum ini disusun berdasar ketentuan pada akreditasi nasional BAN-PT (Badan Akreditasi Nasional Perguruan Tinggi) dan akreditasi internasional IABEE. Pada kurikulum ini penguasaan mahasiswa atas materi Elektronika Penerbangan (Avionik) dan Elektronika Telekomunikasi lebih ditekankan. Alur mata kuliah pada kurikulum 2019 Teknik Elektro ini juga mengalami sedikit perubahan dari kurikulum 2014 (sebelumnya) sehingga syarat kelulusan dapat diturunkan menjadi 144 SKS. Pada kurikulum ini kompetensi lulusan konsentrasi Elektronika Penerbangan ditingkatkan. Beberapa mata kuliah Avionik ditambahkan, misalnya: Sistem Kendali Terbang dan Praktikum Avionik. Target diberlakukannya ini adalah: materi Elektronika Penerbangan dan Elektronika Telekomunikasi dapat lebih mudah dan cepat diserap, mahasiswa dapat menyelesaikan studi tepat waktu dalam 8 (delapan) semester, dan lebih banyak materi mata kuliah yang digunakan di dunia kerja. Kurikulum ini diberlakukan secara penuh mulai mahasiswa baru angkatan 2019. Sementara bagi mahasiswa angkatan sebelumnya dikenakan menggunakan sistem transisi. Sehingga materi avionik yang mereka dapatkan tidak selengkap mahasiswa 
angkatan 2019. Mahasiswa sebelum angkatan 2019 tidak dapat mendapat materi avionik secara menyeluruh kecuali jika mereka mengikuti kembali kuliah di Teknik Elektro.

Untuk mengatasi hal tersebut, Himpunan Mahasiswa Teknik Elektro (HMTE) berusaha menjembatani ketimpangan kompetensi lulusan antar angkatan. Usaha tersebut diwujudkan dengan mengadakan kegiatan pelatihan dan pendalaman avionik bagi mahasiswa dan alumni prodi Teknik Elektro ITDA. Meski demikian, pelatihan yang dilaksanakan secara daring ini dapat diikuti oleh masyarakat umum sehingga ilmu dan pengetahuan tentang avionik dapat disebarluaskan ke masyarakat.

Di antara materi yang baru di kurikulum 2019 adalah tentang Dead Reckoning dan Attitude and Heading Reference System (AHRS). Keberadaan sistem ini menjadikan suatu pesawat terbang dapat mengetahui data sikap dan sudut hadap pesawat saat ini. Bersama data lokasi dari satelit, data tersebut menjadi masukan untuk keperluan navigasi darat dan udara [1] [2]. Materi penggabungan data tersebut merupakan bagian yang tak terpisahkan dari materi pembelajaran navigasi pesawat di perguruan tinggi [3]. Sistem yang merupakan salah satu bagian terpenting dari sistem navigasi pesawat terbang akan terus dikembangkan [4] [5].

Tema AHRS ini saat ini menjadi bagian menarik di dunia penerbangan. Hal ini dikarenakan sudah tersedia sensor-sensor AHRS yang dibuat dengan teknologi micro-electromechanical system (MEMS) [6] [7]. Hal ini membuat system ini mulai diterapkan dalam skala kecil [8], misalnya: drone mini dan robot mobil [9]. Penentuan sikap dan sudut hadap pesawat ini juga dapat dengan mudah dilakukan menggunakan sensor yang ada di smartphone [10] [11]. Dengan demikian materi avionik khususnya AHRS ini diharapkan dapat diterapkan oleh masyarakat khususnya penggemar bidang kedirgantaraan.

\section{METODE}

Sebelum melaksanakan metode yang akan dilaksanakan, tim telah melakukan obsercvasi mengenai metode yang tepat untuk dilakukan. Beberapa kekuatan, kelamahan, peluang dan ancaman dalam memberikan pengetahuan tentang avionik kepada masyarakat dapat dituangkan dalam Tabel 1.

Tabel 1. Kekuatan, kelemahan, peluang dan ancaman yang ada

\begin{tabular}{|c|c|c|}
\hline & Kekuatan & Kelemahan \\
\hline Internal & $\begin{array}{l}\text { 1. Penguasaan materi avionik para dosen } \\
\text { 2. Penelitian tentang avionik telah banyak } \\
\text { dilakukan para dosen } \\
\text { 3. Tersedinya fasilitas untuk melakukan } \\
\text { webinar }\end{array}$ & $\begin{array}{l}\text { Belum bolehnya diadakan seminar dengan } \\
\text { tatap muka langsung }\end{array}$ \\
\hline Eksternal & $\begin{array}{l}\text { 1. Dunia avionik akan terus berkembang } \\
\text { 2. Belum banyak masyarakat yang } \\
\text { mengetahui tentang avionik }\end{array}$ & $\begin{array}{l}\text { 1. Belum banyak masyarakat yang } \\
\text { mengetahui tentang pentingnya avionik } \\
\text { 2. Belum bolehnya masyarakat berkumpul } \\
\text { untuk menghadiri seminar }\end{array}$ \\
\hline
\end{tabular}

Dari Tabel 1 tersebut, dapat disusun strategi yang diterapkan dalam penyampaian materi avionik. Materi avionik harus:

1. Disampaikan dengan bentuk seminar

2. Penyampaian menggunakan metode daring

3. Materi harus dapat dinikmati seluruh lapisan masyarakat kapan saja dan di mana saja.

Format yang tepat untuk pelatihan ini adalah dalam bentuk webinar. Sasaran webinar ini adalah:

1. Para mahasiswa yang sedang/akan belajar avionik, yaitu mahasiswa Teknik Elektro khususnya dari ITDA beserta para alumni

2. Siswa dan guru SMK penerbangan

3. Masyarakat umum.

Perencanaan seluruh kegiatan pelatihan telah dijalankan sejak lama dan dikomunikasikan dengan berbagai pihak. Kegiatan ini merupakan pemberian materi pengenalan tentang Attitude and Heading Reference System (AHRS) yang digunaka dalam navigasi pesawat terbang. Kegiatan ini bagian dari kegiatan pengabdian kepada masyarakat dalam bentuk webinar Pengenalan Avionik kepada Himpunan Mahasiswa dan Alumni Teknik Elektro ITDA yang dilaksanakan pada Rabu - Kamis, 24 - 25 Februari 2021 sebagaimana Tabel 2. 
Tabel 2. Rangkaian kegiatan pengabdian masyarakat

\begin{tabular}{llcl}
\hline \multicolumn{1}{c}{ Hari, tanggal } & \multicolumn{1}{c}{ Penyaji } & Program Studi & \multicolumn{1}{c}{ Materi } \\
\hline $\begin{array}{l}\text { 24 Februari 2021 } \\
\text { Ir. Sutjianto, M.T. }\end{array}$ & T. Elektro & Pengenalan Avionik \\
& Lasmadi, S.T., M.Eng. & T. Elektro & Pengenalan Dead Reckoning \\
& $\begin{array}{l}\text { Freddy Kurniawan, S.T., } \\
\text { M.T. }\end{array}$ & T. Elektro & $\begin{array}{l}\text { Pengenalan Attitude \& Heading } \\
\text { Reference System }\end{array}$ \\
& $\begin{array}{l}\text { Paulus Setiawan, S.T., } \\
\text { Kamis, }\end{array}$ & Aeronautika & Pengenalan Autopilot \\
25 Februari 2021 & $\begin{array}{l}\text { M.T. } \\
\end{array}$ & $\begin{array}{l}\text { Deny Dermawan, S.T., Elektro } \\
\text { M.Eng. }\end{array}$ & Teknik Kendali Digital \\
\end{tabular}

Pelaksanaan pelatihan menggunakan zoom dan disiarkan langsung melalui youtube. Panitia juga menyebarluaskan informasi webinar ini kepada para siswa SMA dan SMK Penerbangan dan masayarakat luas untuk mengikuti pelatihan ini secara daring.

\section{HASIL DAN PEMBAHASAN}

\subsection{Pelaksanaan Kegiatan}

Kegiatan ini diselenggarakan melalui media zoom. Lokasi penyelenggaraan Abdimas terletak di kampus Institut Teknologi Dirgantara Adisutjipto Yogyakarta. Peta lokasi kegiatan ini dapat dilihat pada Gambar 1. Kegiatan pada hari pertama dimulai pukul 09.00 WIB dengan pembukaan oleh master of ceremony (MC), yaitu mahasiswa Teknik Elektro angkatan 2018 bernama Refni Arianti yang berada di Padang. Setelah itu diikuti dengan sambutan oleh Kepala LPPM ITDA Dr. Okto Dinaryanto, S.T., M.M., M.Eng. Setelah itu, diikuti dengan pemaparan materi sebagaimana Tabel 2. Bertindak sebagai moderator adalah Ibu Ndaru Atmi Purnami, S.Si., M.Sc.

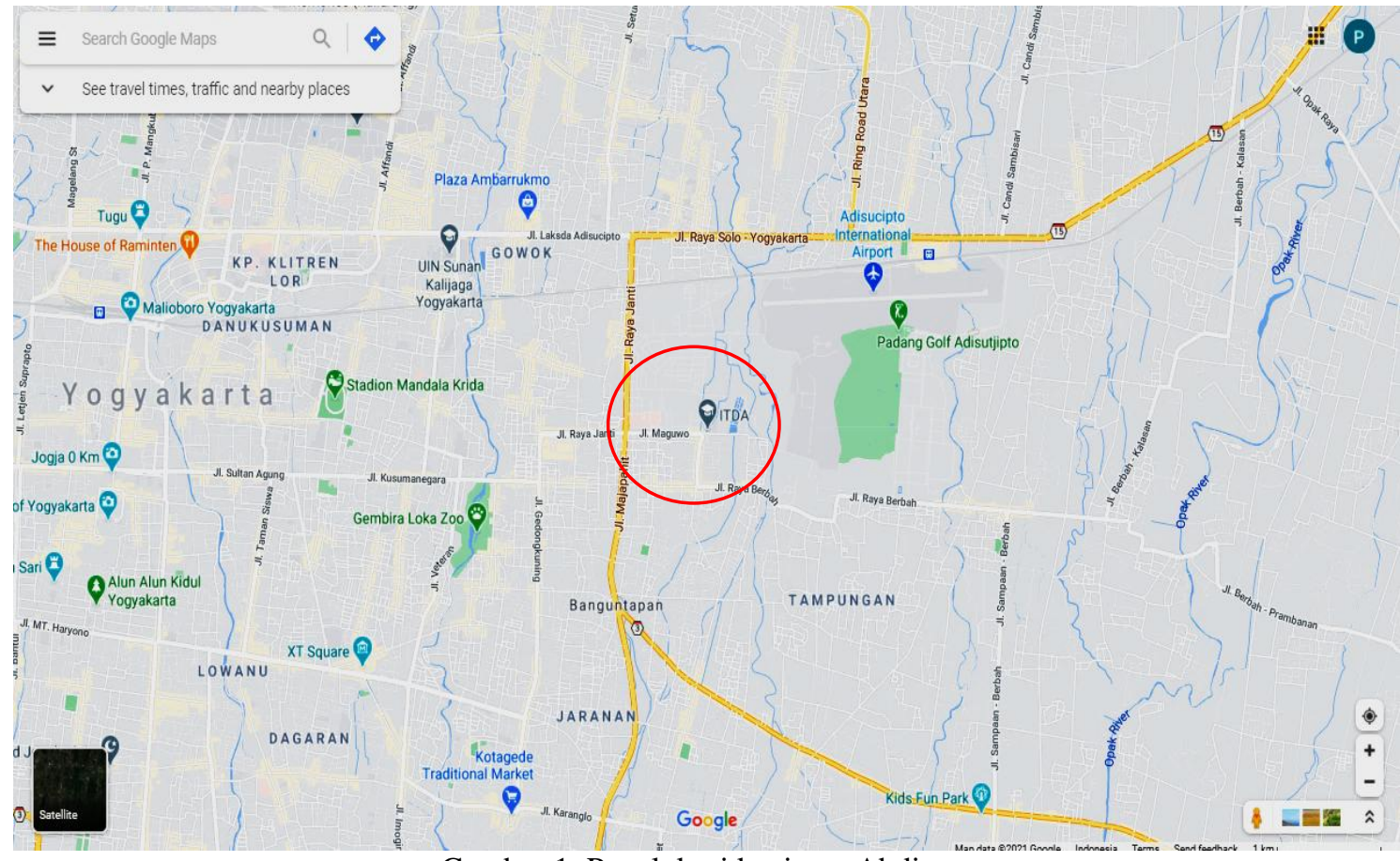

Gambar 1. Peta lokasi kegiatan Abdimas

Materi pertama pada hari pertama adalah Pengenalan Avionik yang disampaikan oleh Ir. Sutjianto S., M.T. Materi ini sekaligus sebagai penenalan awal masyarakat tentang avionik. Materi ini berisi: Pengertian dan fungsi sistem avionik di pesawat terbang, Aircraft Communication System, Aircraft Electricity System, Airborne Collision Avoidance System, Flight control systems, Flight Management systems, Engine Indicating and Crew Alert System (EICAS), Engine and Flight System Monitoring, Navigation System, Attitude Direction Indicator (ADI), Electronic Attitude Direction Indicator (ADI), Horizontal Situation Indicator (HSI), 
Electronic Horizontal Situation Indicator (EHSI), dan Instrument Landing System (ILS). Materi tentang instrumen tersebut diteruskan dengan teknologi tampilan di cockpit yang meliputi pengenalan: Glass Cockpit, Primary Flight Display and Navigation Display, HUD Technology.

Materi selanjutnya adalah tentang Pengenalan Dead Reckoning yang disampaikan oleh Lasmadi, S.T., M.T. Pada sesi ini dijelaskan tentang: memperkirakan posisi pesawat (navigasi), Wind Triangle, Inertial Navigation Systems (INS), dan Inertial Navigation Principles. Kemudian, pada sesi ketiga baru diberikan penjelasan tentang Attitude and Heading Reference System. Materi ini berisi:

1. Pengertian dan fungsi Attitude and Heading Reference System (AHRS)

2. Komponen AHRS: sensor gyroscope, accelerometer, dan magnetometer sensors dengan 3-tingkat kebebasan (3-DoF), dan central processing unit (CPU)

3. Axis pesawat terbang

4. Penentuan attitude dan heading, meliputi:

a. Penentuan attidute: sudut roll dan pitch dapat ditentukan dari sensor akselerometer

b. Penentuan heading: yaw dapat ditentukan dari sensor magnetometer

c. Penentuan attidute dan heading juga dapat dilakukan dari sensor giroskop

d. Penggabungan data attitude dan heading dari sensor akseleerometer-magnetometer dan giroskop dilakukan dengan Kalman filter.

Sebagian materi ini merupakan pengembangan hasil penelitian dosen dengan mahasiswa ITDA [12] [13] [14] [15]. Dengan demikian, pemberian materi avionik ini menjadi salah satu upaya diseminasi hasil penelitian kepada masyarakat. Sebagian tayangan di sesi materi AHRS dapat dilihat pada Gambar 2.

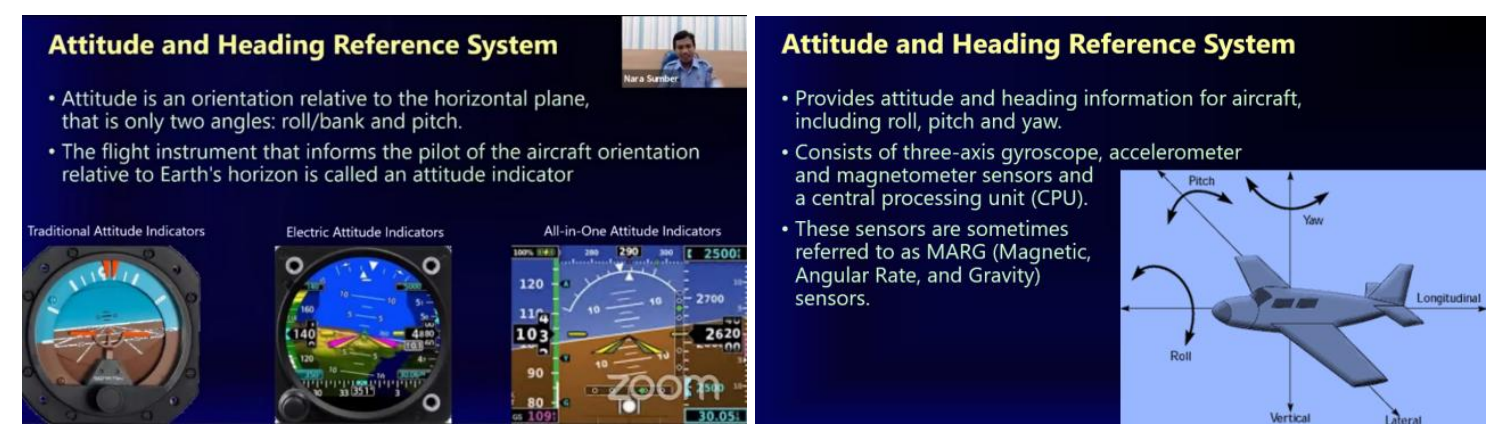

Gambar 2. Sebagian tampilan materi tentang AHRS

Materi disampaikan dalam bentuk slide presentasi sederhana, yaitu poin-poin pengerjaan, bukan sekedar teori. Sementara sebagian besar kegiatan pelatihan dilakukan dengan interaksi langsung bersama para peserta. Dengan bantuan dari beberapa staf di bagian TIK dan mahasiswa, kegiatan ini dapat berjalan dengan lancar.

Untuk dapat lebih menyebarluaskan ilmu dan pengetahuan tentang avionik ini, bagi masyarakat yang belum sempat mengikuti webinar, dapat melihat rekaman kegiatan ini:

1. Rekaman setiap materi secara terinci dapat disaksikan di Playlist Official Channel Teknik Elektro ITDA di https://www.youtube.com/playlist?list=PL-aJ_2SurzNAe4Cg1GnRJVMQVwycWMyyC.

2. Rekaman utuh webinar hari pertama dapat dilihat di Official ITDA Channel di https://www.youtube.com/watch?v=hziRS1k15T8.

3. Rekaman utuh webinar hari kedua dapat dilihat di Official ITDA Channel di https://www.youtube.com/watch?v=93Aiu0CByf8\&t=20s

\subsection{Peserta Pengabdian}

Peserta webinar ini adalah 159 orang, di antaranya meliputi: mahasiswa anggota Himpunan Mahasiswa Teknik Elektro, alumni, SMA dan SMK Penerbangan, Universitas Dirgantara Marsekal Suryadarma. Tampilan sesi foto di hari pertama dan kedua dapat dilihat pada Gambar 3 dan 4. 


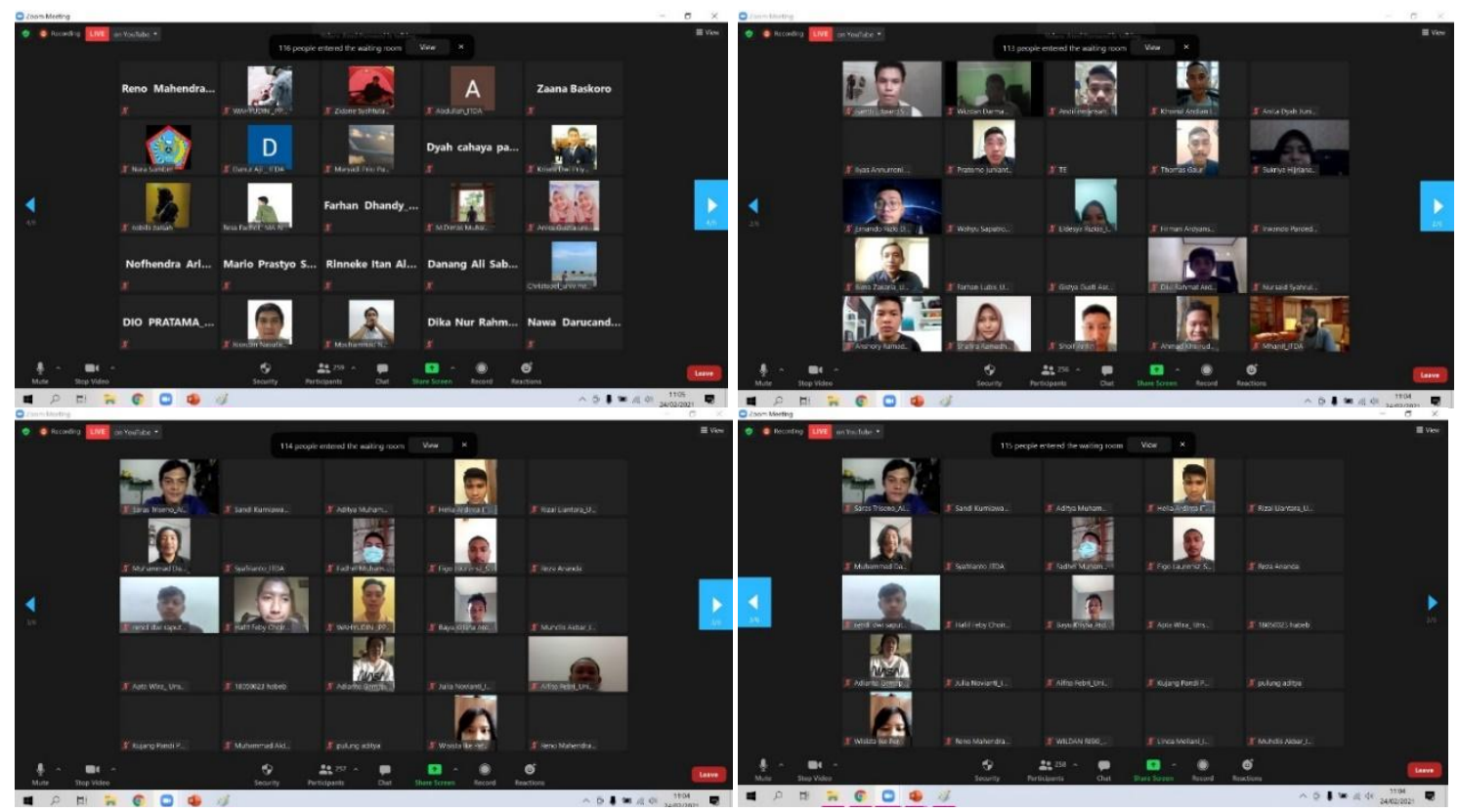

Gambar 3. Sebagian tampilan sesi foto webinar hari pertama

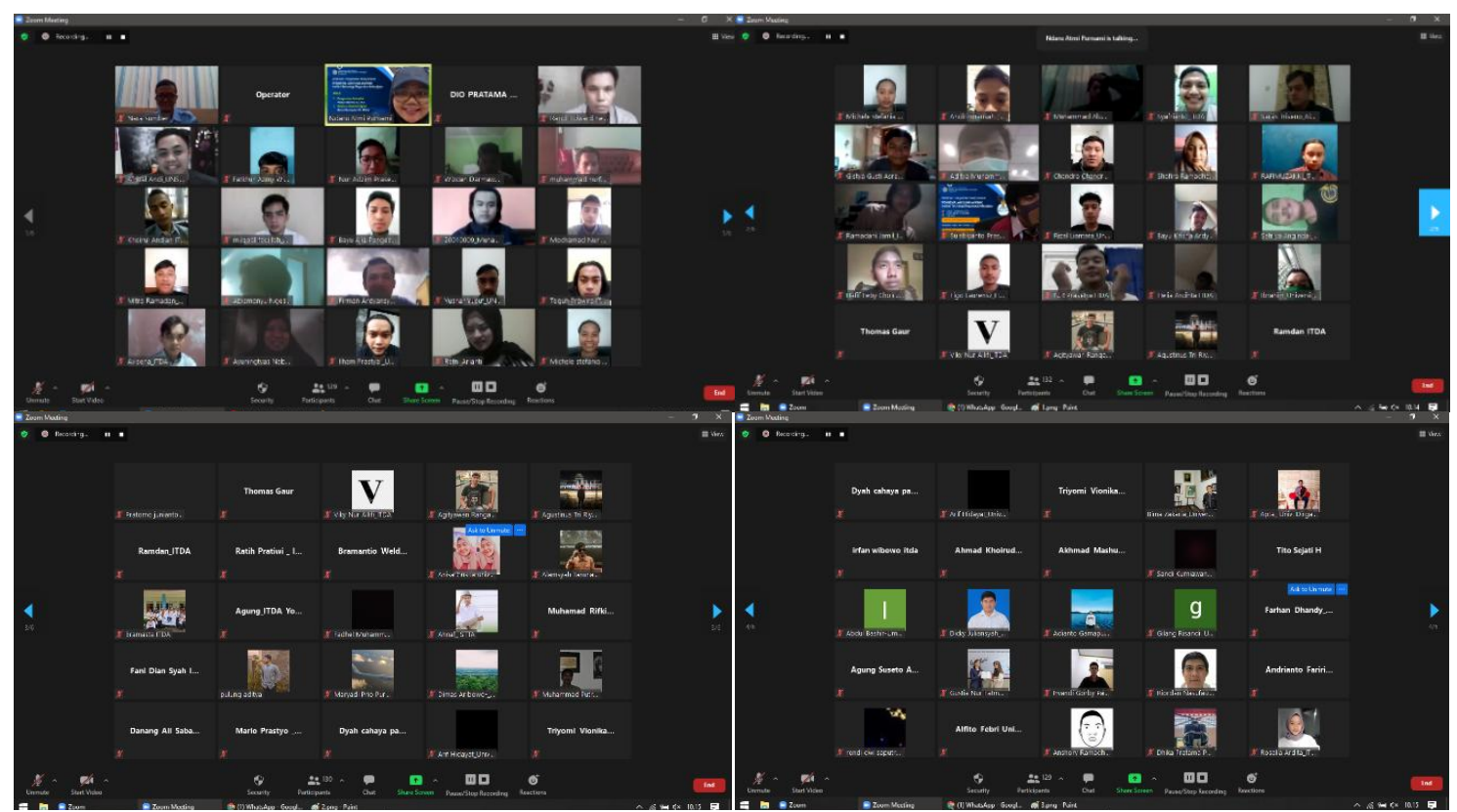

\subsection{Pembahasan}

Gambar 4. Sebagian tampilan sesi foto webinar hari kedua

Webinar ini telah dapat berjalan sesuai harapan. Dari kuesioner yang telah disebarkan panitia kepada peserta webinar, sebanyak $83,3 \%$ peserta dapat dengan mudah memahami materi webinar; sedangkan peserta lain menganggap biasa saja dan tidak mengalami kesulitan memahami materi webinar. Beberapa peserta juga memberikan pertanyaan kepada narasumber. Dari jawaban narasumber, $91,7 \%$ peserta berpendapat narasumber dapat menjawab dengan baik atas pertanyaan yang diberikan peserta. Persentasi tersebut dapat dilihat pada Gambar 5. 
Apakah pemateri mempresentasikan isi materi dengan baik dan mudah dimengerti?

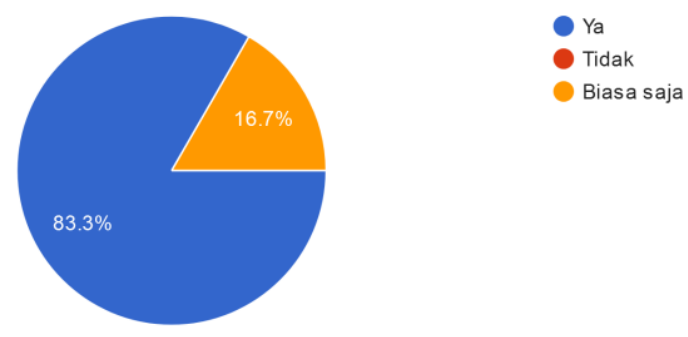

Apakah pemateri memberikan jawaban terhadap pertanyaan peserta dengan baik?

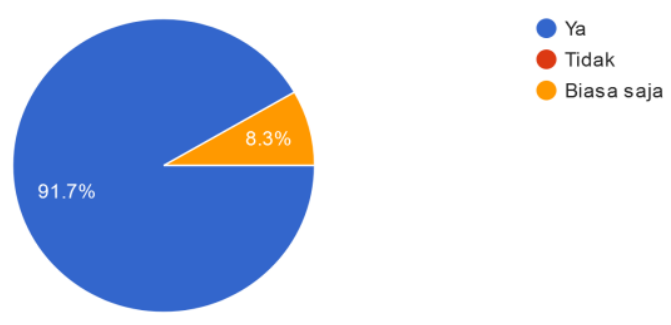

Gambar 5. Jawaban responder atas materi webinar

Antusiasme para peserta juga dapat terlihat dari jawaban kuesioner tentang materi yang mastinya diberikan pada webinar mendatang. Sebagian besar peserta mengharapkan adanya pemberian materi dasar tentang bagaimana sebuah pesawat dapat terbang sebagaimana hasil kuesioner pada Gambar 6. Dari sini terlihat bahwa pengenalan tentang dunia penerbangan masih diperlukan bagi masyarakat, sehingga kegiatan pengabdian kepada masyarakat dalam bentuk webinar pengenalan dunia penerbangan dan avionik dapat diadakan di masa mendatang.

Menurut Anda, apakah materi berikutnya yang sebaiknya disampaikan untuk memberikan pengetahuan kepada masyarakat tentang dunia penerbangan?

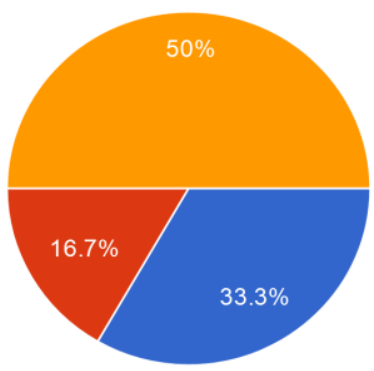

Keselamatan Penerbangan

Avionics lanjut

Pengetahuan bagaimana pesawat dapat terbang

Lainnya

Gambar 6. Tema berikutnya yang diharapkan peserta webinar

\section{KESIMPULAN}

Berdasar pada hasil kegiatan yang telah dipaparkan di muka didapat kesimpulan bahwa kegiatan pengabdian pada masyarakat ini telah dapat terlaksana dengan baik sesuai dengan tujuan yang diharapkan. Kegiatan ini juga dapat diadakan kembali di masa mendatang karena masih dibutuhkan masyarakat khususnya penggemar dunia kedirgantaraan. 


\section{DAFTAR PUSTAKA}

[1] Rui Sun, Yuanxi Yang, Kai-Wei Chiang, Thanh-Trung Duong, Kuan-Ying Lin, Guang-Je Tsai, "Robust IMU/GPS/VO Integration for Vehicle Navigation in GNSS Degraded Urban Areas," IEEE Sensors Journal, vol. 20, no. 17, pp. 10110-10122, 2020.

[2] Sheng Zhao, Yiming Chen, Jay A. Farrell, "High-Precision Vehicle Navigation in Urban Environments Using an MEM's IMU and Single-Frequency GPS Receiver," IEEE Transactions on Iintelligent Transportation Systems, vol. 17, no. 10, pp. 2854-2867, 2016.

[3] Matthew B. Rhudy, Roger A. Salguero, Keaton Holappa, "A Kalman Filtering Tutorial for Undergraduate Students," International Journal of Computer Science \& Engineering Survey (IJCSES), vol. 8, no. 1, 2017.

[4] Romy BudhiWidodo, Chikamune Wada, "Attitude Estimation Using Kalman Filtering: External Acceleration Compensation Considerations," Journal of Sensors, vol. 2016, 2016.

[5] Lubin Chang, Feng Zha, Fangjun Qin, "Indirect Kalman Filtering Based Attitude Estimation for Low-Cost Attitude and Heading Reference Systems," IEEE/ASME Transaction on Mechatronics, vol. 22, no. 4, 2017.

[6] Pengge Huang, Haojie Lv, "The Design of Attitude Heading Reference System Based on MEMS," in 2017 IEEE 6th Data Driven Control and Learning Systems Conference, Chongqing, China, 2017.

[7] Yentze Ko, Xiaodong Geng, Yuyu Lai, Xiao Ma, Xiaole Cui, Guangyi Shi, "Moving Vehicle Attitude Tracking Algorithm based," in Proceedings of the 1st IEEE International: Conference on Micro/Nano Sensors for AI, Healthcare and Robotics, Shenzhen, China, 2018.

[8] Long Zhao, Qing Yun Wang, "Design of an Attitude and Heading Reference System Based on," Mathematical Problems in Engineering, 2013.

[9] Lasmadi, F. Kurniawan, D. Dermawan, GNP. Pratama, "Mobile Robot Localization via Unscented Kalman Filter," in 2019 International Seminar on Research of Information Technology and Intelligent Systems (ISRITI), Yogyakarta, 2019.

[10] Thibaud Michel, Pierre Genev`es, Hassen Fourati, Nabil Laya"1da, "On Attitude Estimation with Smartphones," in 2017 IEEE International Conference on Pervasive Computing and Communications (PerCom), 2017.

[11] Abhijit Suprem, Vishal Deep, Tarek Elarabi, "Orientation and Displacement Detection for Smartphone Device Based IMUs," IEEE Access, vol. 5, pp. 987-997, 2016.

[12] Lasmadi; AI Cahyadi, S. Herdjunanto, R. Hidayat, "Inertial Navigation for Quadrotor Using Kalman Filter with Drift Compensation," International Journal of Electrical and Computer Engineering (IJECE), vol. 7, no. 5, pp. 2596-2604, 2017.

[13] MAR. Wicaksono, F. Kurniawan, Lasmadi, "Kalman Filter untuk Mengurangi Derau Sensor Accelerometer pada IMU Guna Estimasi Jarak," AVITEC, vol. 2, no. 2, 2019.

[14] Briyan Yoga Sandi, Freddy Kurniawan, Lasmadi, "Estimasi sudut orientasi rigid body dengan menggunakan sensor IMU (Inertial Measurement Unit) dan Magnetometer," in SENATIK, Yogakarta, 2020.

[15] Lasmadi, L., Kurniawan, F., Pamungkas, M. I., "Estimasi Sudut Rotasi Benda Kaku Berbasis IMU Menggunakan Kalman Filter," AVITEC, vol. 3, no. 1, pp. 57-68, 2021. 
